\title{
Tuberculosis following programmed cell death receptor-1 (PD-1) inhibitor in a patient with non-small cell lung cancer. Case report and literature review
}

\author{
Aasir M. Suliman ${ }^{1}$. Shaza A. Bek ${ }^{2}$ Mohamed S. Elkhatim² - Ahmed A. Husain ${ }^{3} \cdot$ Ahmad Y. Mismar $^{1}$. \\ M. Z. Sharaf Eldean ${ }^{4} \cdot$ Zsolt Lengyel $^{5} \cdot$ Shereen Elazzazy $^{6}$ (D) Kakil I. Rasul ${ }^{2} \cdot$ Nabil E. Omar $^{6}{ }^{\circledR}$
}

Received: 12 May 2020 / Accepted: 11 September 2020 / Published online: 17 October 2020

(c) The Author(s) 2020

\begin{abstract}
Immune checkpoint inhibitors (ICIs) - anti-programmed death-1 (PD-1) and their ligands (PD-L1 and PD-L2) have become widely used in the treatment of several malignancies. Many immune-related adverse events (irAEs) have been linked to these agents. Nonetheless, tuberculosis (TB) reactivation during their use is increasingly recognized and reported. Herein, we present a 58-year-old lady with advanced non-small cell lung cancer (NSCLC) ALK-negative, EGFR wild, and PD-L1 immune histochemistry (IHC) strongly positive in $95 \%$ of tumor cells, on ongoing treatment with Pembrolizumab as a firstline monotherapy. Our patient presented with 1-week history of productive cough and high-grade fever. Further workup yielded the diagnosis of pulmonary tuberculosis after her Pembrolizumab sixth cycle with positive AFB smear and TB PCR from BAL (rifampin resistance not detected), with negative HIV status. Hence, immunotherapy was held, and patient was commenced on anti-TB regimen. History revealed contact with active TB patient over the past decade, without previous documentation of latent TB or previous TB infection. Her sputum AFB smear remained persistently positive 4 weeks through anti-TB regimen course. Later, the patient was discharged after her sputum was cleared from AFB (two negative sets). In light of pembrolizumab mechanism of action as an immune checkpoint inhibitor, we suspected its implication on reactivating latent TB which was observed in our patient demonstrating features of pulmonary tuberculosis. She was not re-challenged with Pembrolizumab following TB diagnosis.
\end{abstract}

Keywords Tuberculosis · NSCLC · PD-1 inhibitor · Pembrolizumab · Immune related adverse events · Case report

Electronic supplementary material The online version of this article (https://doi.org/10.1007/s00262-020-02726-1) contains supplementary material, which is available to authorized users.

Nabil E. Omar

Nomar4@hamad.qa

1 Department of internal medicine, Hamad General Hospital, Hamad Medical Corporation, Doha, Qatar

2 Department of Medical Oncology, National Center for Cancer Care and Research, Hamad Medical Corporation, Doha, Qatar

3 Department of Infectious Diseases, Communicable Disease Center, Hamad Medical Corporation, Doha, Qatar

\section{Background}

Immune checkpoint inhibitors (ICIs) are a type of cancer immunotherapy that has provided a tremendous breakthrough in the field of oncology [1]. They inhibit inhibitory pathways of immune cells which allow more increased immune cell activity and reduce T-cell exhaustion [2].

4 Department of Pathology, Hamad General Hospital, Hamad Medical Corporation, Doha, Qatar

5 Department of Body Imaging, National Centre for Cancer Care and Research, Hamad Medical Corporation, Doha, Qatar

6 Pharmacy Department, National Centre for Cancer Care and Research, Hamad Medical Corporation, 3050 Doha, Qatar 
Currently approved checkpoint inhibitors target the cytotoxic T-lymphocyte-associated protein 4 (CTLA4), programmed death receptor-1 (PD-1), and programmed death-ligand 1(PD-L1).

Recognition of cancer cells by the toxic $\mathrm{T}$ lymphocytes plays an essential role in the malignant cell killing. Cancer cells may evade this process by expressing programmed death-ligand 1 (PD-L1), which binds to the programmed death receptor-1 (PD-1) on T-cell surface [3]. This interaction (PD-L1/PD-1) leads to inhibition of cytokines and T-cell proliferation, leading to cancer cells equivocating the killing process. Consequently, immunotherapy-mediating inhibition of (PD-L1/PD-1) pathway has revolutionized cancer treatment [4].

Interestingly enough, the role of ICIs has been studied in infectious diseases as well [5]. Various human studies and animal models suggest that immune system activated by PD-1/PD-L1 blockade is effective in targeting certain viral, bacterial, and fungal pathogens by limiting T-cell dysfunction $[5,6]$.

Nonetheless, in sharp contrast with other pathogens that cause chronic infection, accumulating reports demonstrate the occurrence of Mycobacterium tuberculosis (MTB) infection during immunotherapy with ICIs (Table 1).

Herein, we present a patient with advanced non-small cell lung cancer (NSCLC) who developed pulmonary tuberculosis following treatment with pembrolizumab monotherapy as first-line treatment.

\section{Case presentation}

A 58-year-old female patient, with 20 pack-year smoking history, and type 2 Diabetes mellitus for 2 years. She presented in 2015, with an incidental right apical lung mass suggestive of Pancoast tumor as demonstrated on her chest CT (Fig. 1a, b) following abnormal chest X-ray. The patient refused further investigations at the time. 3 years later, she was admitted to with sepsis secondary to acute cholecystitis.

Hospital course was complicated by left anterior cerebral artery (ACA) stroke. During the admission, further workup of her lung mass was pursued through biopsy from a left cervical lymph node, which affirmed the diagnosis of metastatic pulmonary adenocarcinoma (stage IV) (Fig. 2a, b).

Immunohistochemistry (IHC) report was strongly positive for PD-L1 in 95\% of the tumor cells (Fig. 3a, b), negative ALK gene rearrangement, and no EGFR mutation was detected.

Later on, the patient was started on immunotherapy pembrolizumab monotherapy, $200 \mathrm{mg}$ every 3 weeks, as first-line treatment. PET CT following six cycles of pembrolizumab showed mixed response with overall moderate progression (Fig. 4a, b).
On 29th July 2019, she presented with a 1-week history of productive cough, high-grade fever, tachycardia, and low oxygen saturation (Temp: 39.2, HR: 130, SPO2: $91 \%$ on room air). Chest X-ray revealed a significant opacity in the left mid and lower lung zones (Fig. 5).

CT angiogram was done and showed left-sided large pulmonary consolidative mass lesion and areas of cavitation. (Fig. 6).

She was treated with antibiotics as community-acquired pneumonia; however, she continued to spike fever. The initial microbiological workup was negative. Bronchoscopy and bronchoalveolar lavage (BAL) showed positive AFB smear and TB PCR (rifampin resistance not detected). No workup for pulmonary tuberculosis was done prior to initiation of ICPs.

The patient home medications prior to the last hospital admission included; atorvastatin $40 \mathrm{mg}$ oral tablet once daily, aspirin $100 \mathrm{mg}$ oral tablet once daily and vitamin D2 capsules oral once weekly. During her course of immunotherapy, she did not experience any immune-related adverse events (irAEs) requiring prednisone prior to development of TB.

She was started on anti-TB medications (RIFA four). Further history revealed that she had sick contact with active TB patient 10 years ago, but there was no documentation of latent TB or previous TB infection. Her HIV status was negative. Sputum AFB smear found positive and cleared 6 weeks following anti-TB medications.

2 weeks later, chest X-ray showed new bilateral reticular, and nodular pulmonary infiltrates (Fig. 7).

CT chest was done and confirmed the progression of the disease, with innumerable bilateral lesions and new lesion in segment 6 of the liver (Fig. 8).

Patient was subsequently started chemotherapy with carboplatin and pemetrexed as second line. Repeated PET CT after four cycles of second-line chemotherapy showed Good therapeutic response with near-complete remission of lung, liver, spleen, and lymph nodal involvements (Supplementary figure 9).

The patient remained on chemotherapy and anti-TB medications for a proposed 9-month duration.

\section{Discussion}

TB reactivation is an established adverse effect attributed to many anti-cancer biological agents and with TNF- $\alpha$ inhibitors as well $[7,8]$. The incidence of TB reactivation in cancer patients is higher in hematological malignancies compared to solid tumors. While, among solid tumors, the highest incidence of TB reactivation was reported in lung cancer followed by gastric cancer, breast cancer, liver cancer, and colon cancer, respectively [9]. 


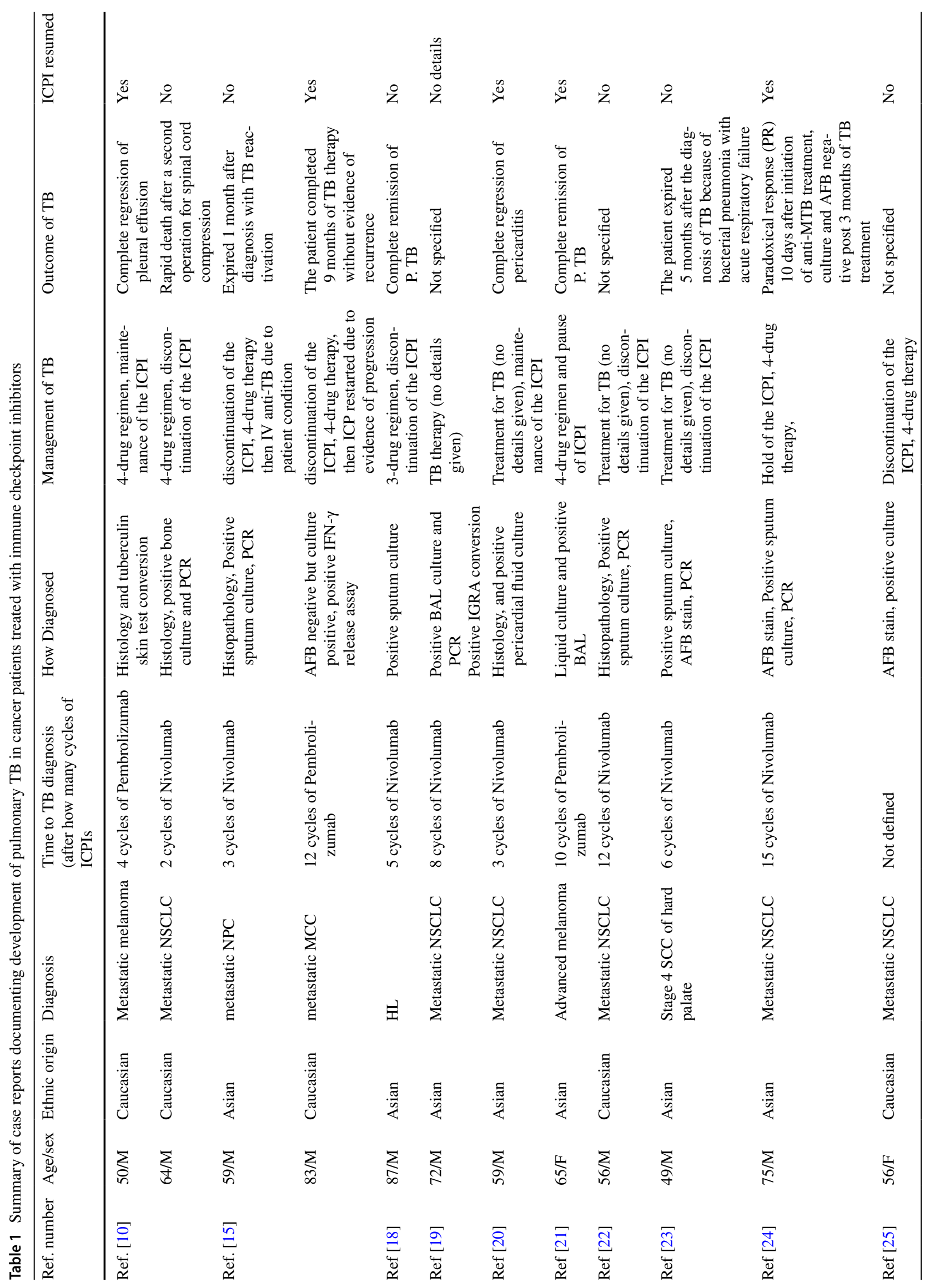


With the expanding use of immune checkpoint inhibitors for the management of cancer, infectious complications of immune checkpoint inhibitors became an emerging adverse effect of these agents, including TB reactivation [10].

The majority of patients infected with tuberculosis will develop a latency state with no signs of disease, with approximately, up to ten percent of those patients may develop active tuberculosis infection [11]. Containments of the infection are mediated by cytokines and the interaction between macrophages and Tymphocytes (CD4 and CD8) [12]. Immunocompromised status including, HIV, organ transplanted patients, and patients receiving immunosuppressive therapy is one of the most critical risk factors for TB reactivation [13].

The exact mechanism of TB reactivation following treatment with these agents remains unclear, with further studies is warranted. However, few preclinical studies in MTB infected PD-1-deficient mice and PD-1 blocked humans describe an increase in the IFN- $\alpha$ production by CD4 T cells which promote more bacterial replication and tissue destruction $[6,14,15]$.

Furthermore, the role of (PD-L1/PD-1) pathway has been studied which has demonstrated its effect on $M$. tuberculosis infection; In mice model, PD-1 deficiency showed significant sensitivity to $M$. tuberculosis infection and high bacillary load after exposure to aerosol infection with M. tuberculosis. PD-1-deficient mice also showed dramatic survival reduction and lung tissue was found to be severely necrotic and inflamed in comparison to the control group [16]. On the other hand, the data about (PD-L1/PD-1) pathway and its role in the cytolytic activity of T. lymphocytes in humans is diversely contradictory [17]. However, multiple reports highlighted the reactivation of pulmonary tuberculosis infection after the use of PD- 1 inhibitors [10, 15, 26, 27, 18-25].

In this paper, ICIs associated MTB infection was extensively searched by expediting all the reported cases through PubMed up to September 2019, with no language restriction applied. In general, 15 reported cases were identified retrieved from 12 articles [10, 15, 26, 27, 18-25], in addition to our case (Table 1). Data showed that all the patients were either Caucasians or Asians, aged from 49 to 87 years and with male predominance.

With respect to their oncological diagnosis, five cases had metastatic non-small cell lung cancer (NSCLC), six cases had metastatic melanoma, two cases had metastatic head and neck squamous cell carcinoma (HNSCC), one case had Hodgkin lymphoma and one case had metastatic Merkel carcinoma.

For the ICIs, eight cases were on nivolumab, six cases were on pembrolizumab, and only one case was on atezolizumab. The time to diagnosis varied among patients and ranged between 4 and 36 weeks. In all patients, no latent TB testing (LTBT) before immunotherapy was done, and it was 

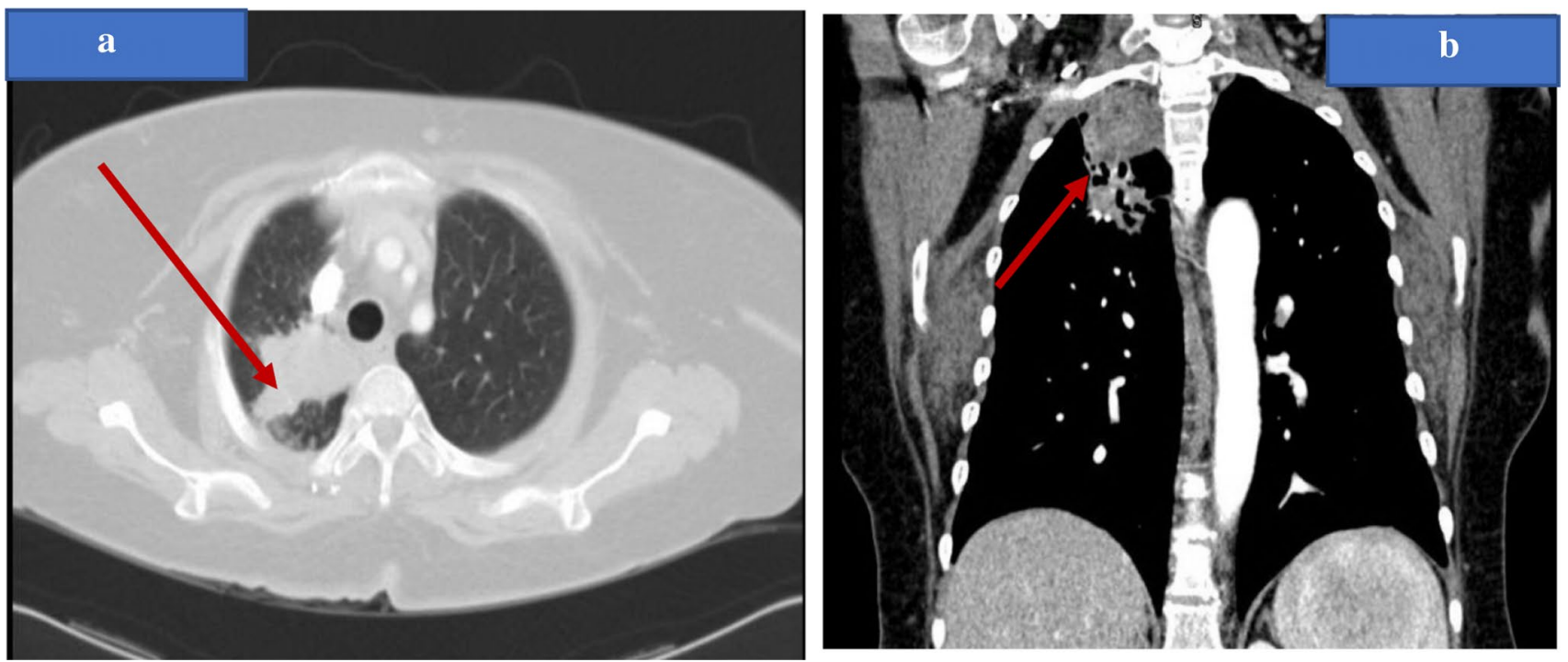

Fig. 1 a, b Chest CT showing a well-defined right apical mass lesion with pleural invasion and possible mediastinal extension, suggestive of Pancoast tumor (red arrow)
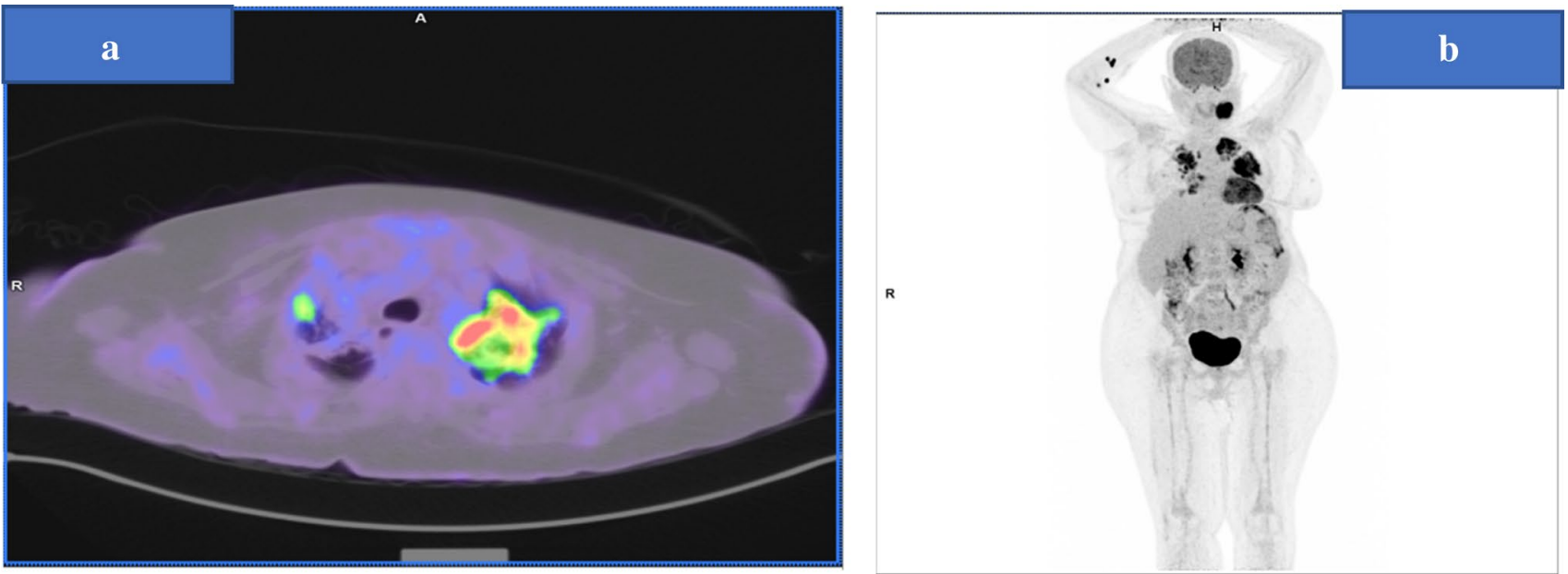

Fig. 2 a Fused FDG PET-CT image with lung window showing intense uptake bilaterally more prominent in the left apical mass. b maximum intensity projection representation of whole body FDG distribution showing metastatic pulmonary adenocarcinoma (stage IV)—note FDG avidity is more on left side

TB infection 10 years ago, but there was no documentation of latent TB or previous TB infection prior to initiation of ICPs. The mixed response noted on 14th July 2019 PET CT (Fig. 4) was not perceived as pseudoprogression-like phenomenon as overt disease progression was confirmed by 26th August 2019 CT chest and abdomen as illustrated (Fig. 8).

ICIs were not resumed in our case and carboplatin plus pemetrexed was initiated instead, as second-line chemotherapy. None of the previously reported cases has used 

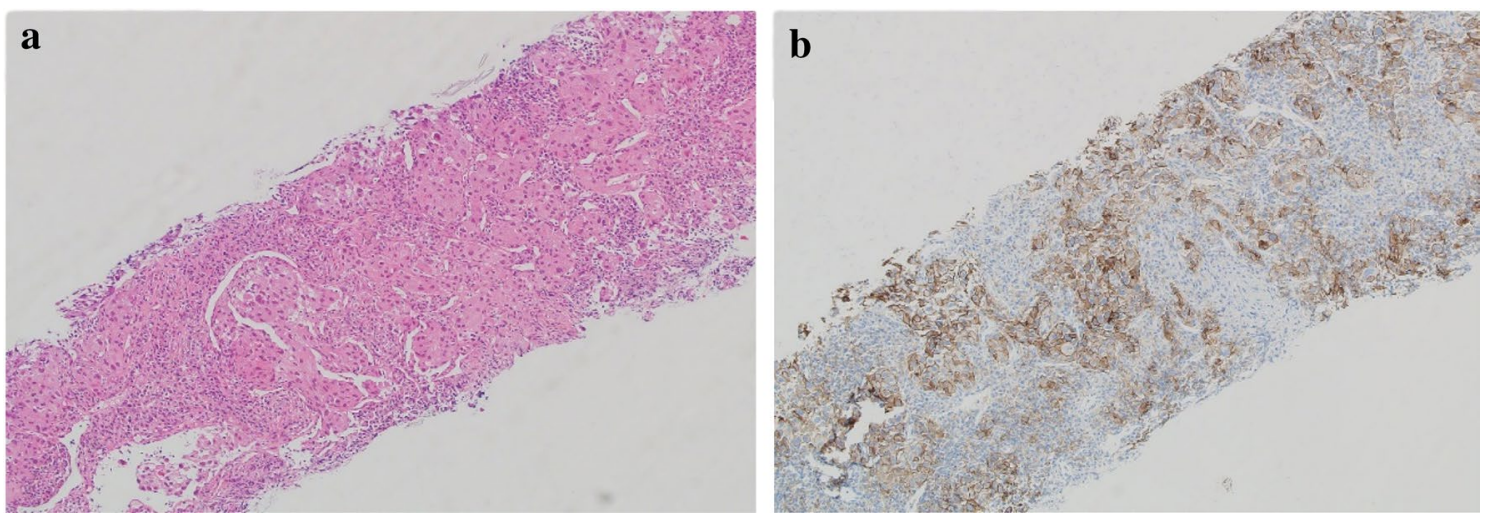

Fig. 3 a H\&E lymph node is extensively infiltrated by nests and sheets of large malignant cells with large irregular-shaped nuclei, prominent nucleoli and abundant eosinophilic cytoplasm. Rare scat-

tered anaplastic cells are also present. b immunohistochemistry showing PDL 1 is strongly positive in $95 \%$ of cells
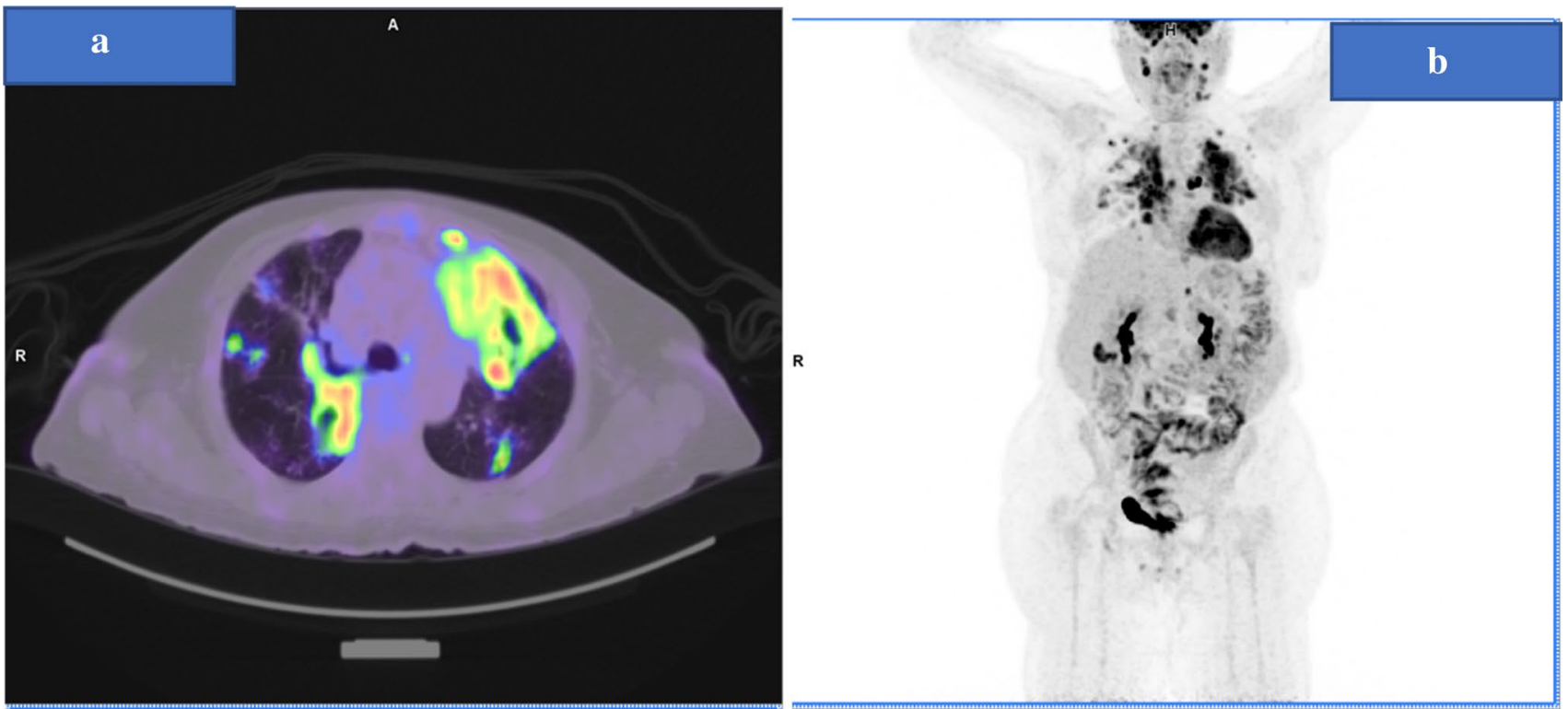

Fig. 4 a, b PET CT (lung window) following six cycles of pembrolizumab showed mixed response with overall moderate progression

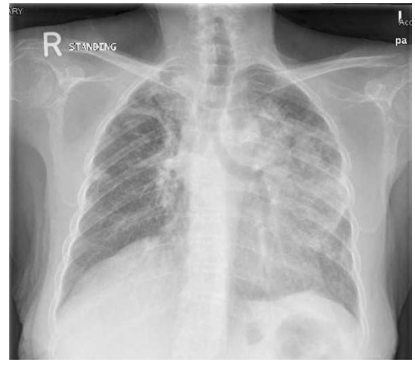

Fig. 5 Chest XR showing large opacity noticed in the left mid and lower lung zones and Right upper zonal nodular and reticular shadowing the traditional chemotherapy as a subsequent therapy to immunotherapy; nonetheless, the outcome of TB in patients receiving cytotoxic chemotherapy for malignancies have been reported in two retrospective studies in South Korea and Japan [28, 29]. In both studies, concurrent chemotherapy was found to be effective and safe for treating cancer patients with active MTB.

In a recent Meta-analysis including United States cancer patients, the risk of active TB was 41/100,000 [30], however, it is significantly higher in high prevalence areas such as South Korea with 3.07/1000 in patients with cancer [31]. It is worth mentioning that the global prevalence 
Fig. 6 CT chest angiogram (lung window) showing consolidation with cavitary lesion bilaterally (red arrow)

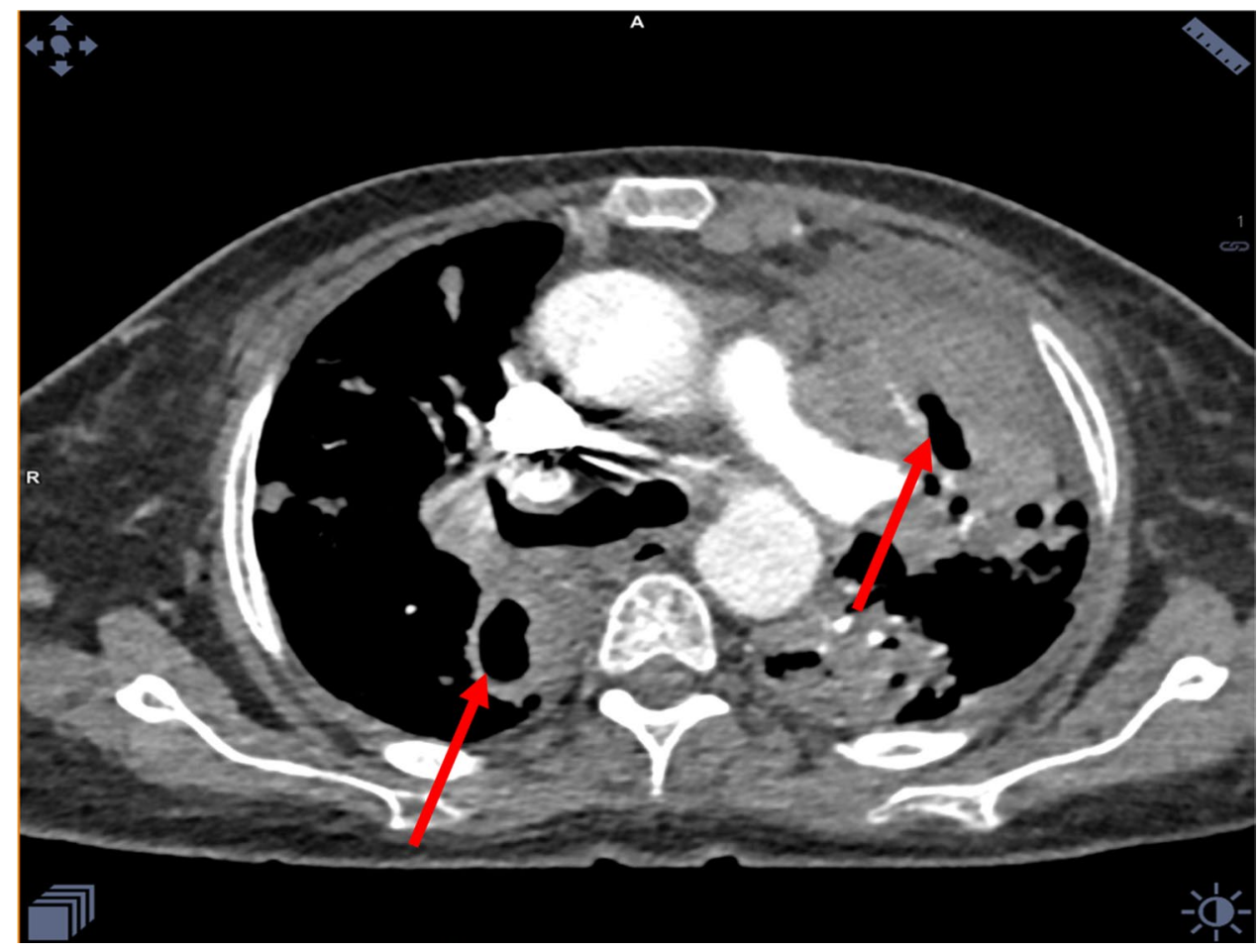

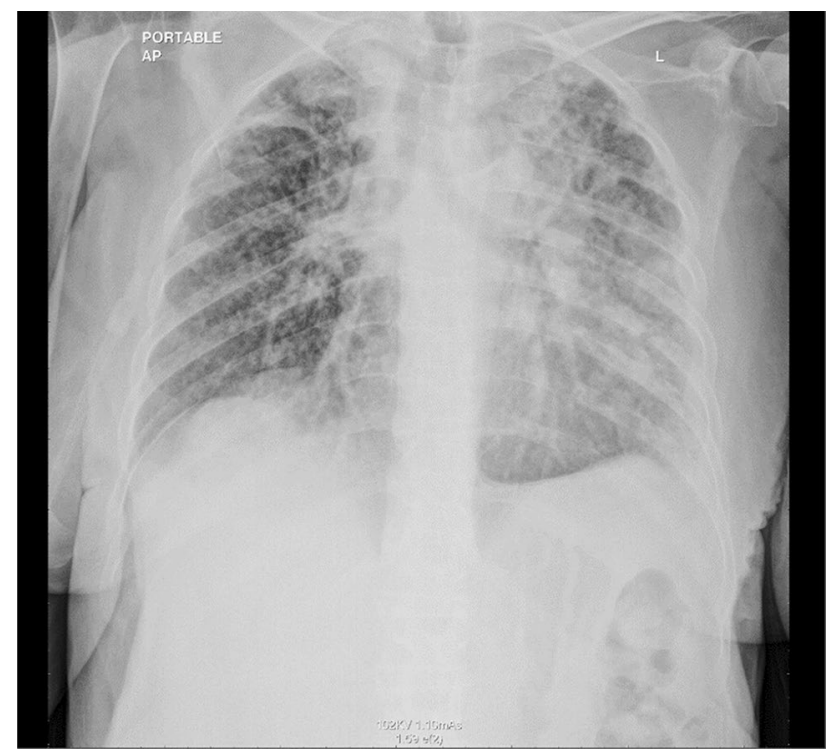

Fig. 7 Chest X-ray showed new bilateral reticular and nodular pulmonary infiltrates.

of latent TB infection in 2014 was estimated to be $23.0 \%$, while the estimate for WHO Eastern Mediterranean
Region which includes the state of Qatar was 16.3 [13.4-20.5] [32].

In 2012, the incidence of tuberculosis in Qatar was $41 / 100,000$. The majority of infected patients $(90 \%)$ was non-national males [33]. Whereas, pulmonary tuberculosis represents around $46 \%$ of active tuberculosis infection [34].

\section{Conclusion}

To our knowledge, this is the first reported case from the Arab and the Middle East region; it reinforces the previous observations of the association between ICIs administration and the development of MTB. Nevertheless, furthers studies in the clinical setting are necessary to establish the exact mechanism involved in this association. Oncologists' awareness and prompt recognition of this potential hazardous consequence are essential. Since there is no clear evidence whether LTBT prior PD-1/PD targeted immunotherapy is required, targeted LTBT before starting ICIs immunotherapy with TB chemoprophylaxis; yet to be explored, particularly in the regions where the MTB prevalence is high. 


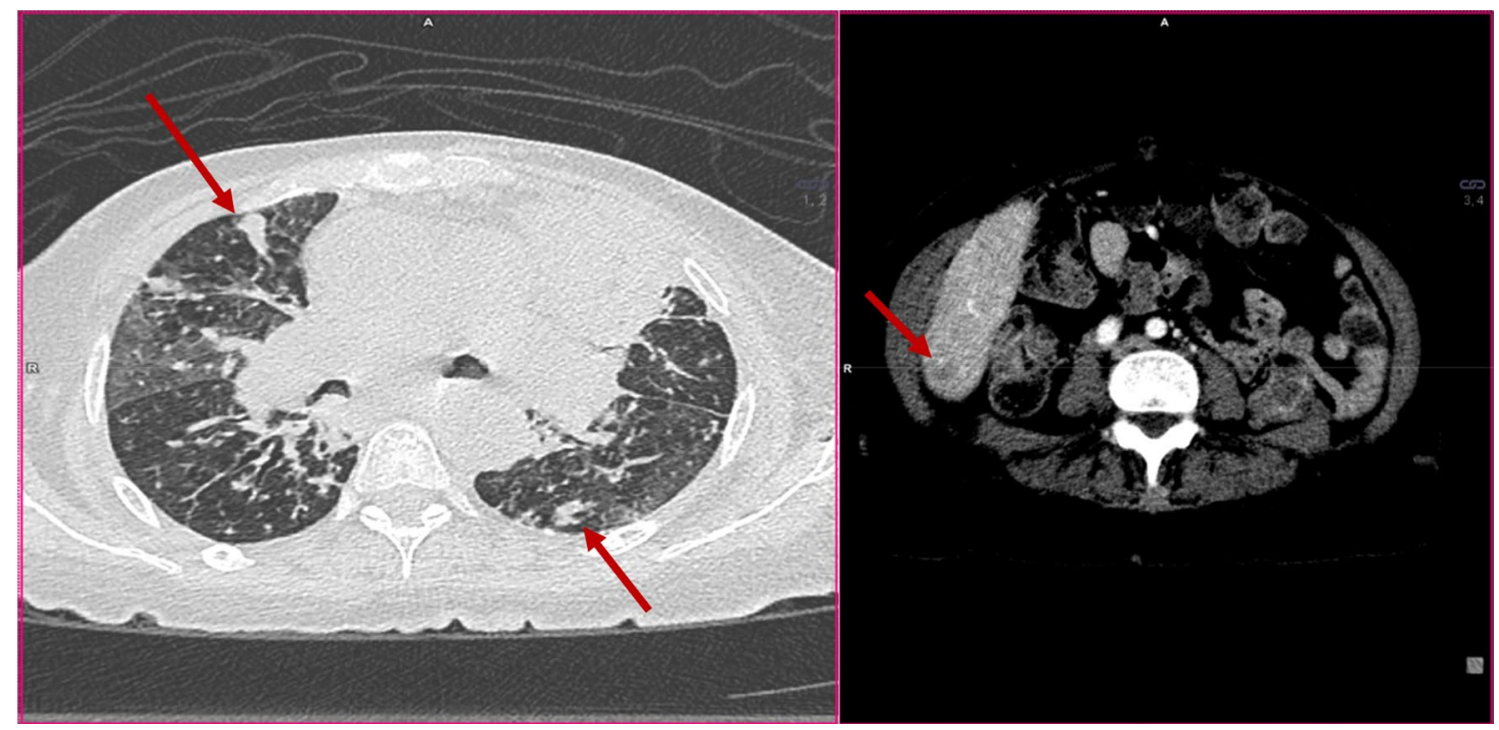

Fig. 8 CT chest confirmed progression of the malignant disease, with innumerable bilateral nodular lesions, and new hypodense lesion in segment 6 of the liver.

Acknowledgements We acknowledge the Qatar National Library for funding the open access publication of this article. We also acknowledge the Medical Research Center at Hamad Medical Corporation for their support.

Author contributions AMS and SAB contributed to the literature review and drafted the initial manuscript; MSE critically revising the paper and helped in manuscript writing; AAH and AYM contributed to data collection and helped in manuscript writing; ZL helped in the radiology figures and helped in manuscript writing; MZS contributed to the pathology section of the case report; SE helped in manuscript writing; KIR managed patient care and revise the final draft of the manuscript; NEO conceived and designed the idea, literature review, data collection, wrote the manuscript, overall organized the case report, supervised the project and proof-reading of the manuscript. All authors gave final approval of the version to be published and agreed to be accountable for all aspects of the work.

Funding Open Access funding provided by the Qatar National Library.

Availability of data and material The datasets used and/or analyzed during the current study are available from the corresponding author on reasonable request.

\section{Compliance with ethical standards}

Conflict of interest The authors report no conflicts of interest in this work.

Ethics approval and consent to participate The case report was approved by the Medical Research Centre at Hamad Medical Corporation and the Hamad Institutional Review Board (IRB) under number MRC-04-20-095.

Consent for publication This case report does not contain any personal identifier of the patient (such as name, photograph ... etc.). It only includes radiological and pathological imaging, which does not con- tain any identifications. A written patient informed consent of patient information, images and publication was signed by the patient.

Open Access This article is licensed under a Creative Commons Attribution 4.0 International License, which permits use, sharing, adaptation, distribution and reproduction in any medium or format, as long as you give appropriate credit to the original author(s) and the source, provide a link to the Creative Commons licence, and indicate if changes were made. The images or other third party material in this article are included in the article's Creative Commons licence, unless indicated otherwise in a credit line to the material. If material is not included in the article's Creative Commons licence and your intended use is not permitted by statutory regulation or exceeds the permitted use, you will need to obtain permission directly from the copyright holder. To view a copy of this licence, visit http://creativecommons.org/licenses/by/4.0/.

\section{References}

1. Darvin P, Toor SM, Sasidharan Nair V, Elkord E (2018) Immune checkpoint inhibitors: recent progress and potential biomarkers. Exp mol med 50(12):1-11

2. Cancer Institute N (2015) Definition of immune checkpoint inhibitor-NCI Dictionary of Cancer Terms-National Cancer Institute [cited 2020 Feb 14] Available at: https://www.cancer.gov/publi cations/dictionaries/cancer-terms/def/immune-checkpoint-inhib itor. Accessed 14 Feb 2020

3. Alsaab HO, Sau S, Alzhrani R, Tatiparti K, Bhise K, Kashaw SK et al (2017) PD-1 and PD-L1 checkpoint signaling inhibition for cancer immunotherapy: mechanism, combinations, and clinical outcome. Front Pharmacol. https://doi.org/10.3389/fphar .2017.00561

4. Chen DS, Irving BA, Hodi FS (2012) Molecular pathways: nextgeneration immunotherapy-inhibiting programmed death-ligand 1 and programmed death-1. Clin Cancer Res 18(24):6580-6587. [cited 2020 Feb 15] Available from: https://www.ncbi.nlm.nih. gov/pubmed/23087408. Accessed 15 Feb 2020 
5. Sharpe AH, Wherry EJ, Ahmed R, Freeman GJ (2020) The function of programmed cell death 1 and its ligands in regulating autoimmunity and infection. Nat Immunol 8: 239-45 [cited 2020 Feb 14] Available from: https://www.ncbi.nlm.nih.gov/pubmed/17304 234. Accessed 15 Feb 2020

6. Tousif S, Singh Y, Prasad DVR, Sharma P, van Kaer L, Das G (20111) T cells from programmed death-1 deficient mice respond poorly to mycobacterium tuberculosis infection. Khader $\mathrm{S}$, editor. PLoS One 6(5):e19864 [cited 2020 Feb 14]. https://dx.plos. org/10.1371/journal.pone.0019864. Accessed 14 Feb 2020

7. Tubach F, Salmon D, Ravaud P, Allanore Y, Goupille P, Bréban M et al (2009) Risk of tuberculosis is higher with anti-tumor necrosis factor monoclonal antibody therapy than with soluble tumor necrosis factor receptor therapy: the 3-year prospective French research axed on tolerance of biotherapies registry. Arthritis Rheum 60(7):1884-1894

8. Dobler CC (2015) Biological agents and tuberculosis: risk estimates and screening strategies. Int J Rheum Dis 18(3):264-267. [cited 2020 Feb 14] Available from: https://www.ncbi.nlm.nih. gov/pubmed/25923605. Accessed 14 Feb 2020

9. Dobler CC, Cheung K, Nguyen J, Martin A (2017) Risk of tuberculosis in patients with solid cancers and haematological malignancies: a systematic review and meta-analysis. Eur Respir J 50(2). [cited 2020 Feb 14]. Available at: https://www.ncbi.nlm. nih.gov/pubmed/28838977. Accessed 14 Feb 2020

10. Picchi H, Mateus C, Chouaid C, Besse B, Marabelle A, Michot JM, et al (2018) Infectious complications associated with the use of immune checkpoint inhibitors in oncology: reactivation of tuberculosis after anti PD-1 treatment [Internet], vol 24. Clin Microbiol Infect Elsevier BV [cited 2020 Feb 14]. p. 216-8. Available at: https://www.ncbi.nlm.nih.gov/pubmed/29269089. Accessed 14 Feb 2020

11. Philips JA, Ernst JD (2012) Tuberculosis Pathogenesis and Immunity. Annu Rev Pathol Mech Dis [Internet] 7(1):353-84. [cited 2020 Feb 15] Available at: https://www.ncbi.nlm.nih.gov/pubme d/22054143. Accessed $15 \mathrm{Feb} 2020$

12. Van Crevel R, Ottenhoff THM, Van der Meer JWM (2002) Innate immunity to Mycobacterium tuberculosis. Clin Microbiol Rev 15:294-309

13. Ai JW, Ruan QL, Liu QH, Zhang WH (2016) Updates on the risk factors for latent tuberculosis reactivation and their managements. Emerg Micro Infect 5:e10

14. Barber DL, Mayer-Barber KD, Feng CG, Sharpe AH, Sher A (2011) CD4 T cells promote rather than control tuberculosis in the absence of PD-1-mediated inhibition. J Immunol 186(3):1598607 [cited 2020 Feb 14] Available at: https://www.ncbi.nlm.nih. gov/pubmed/21172867. Accessed $14 \mathrm{Feb} 2020$

15. Barber DL, Sakai S, Kudchadkar RR, Fling SP, Day TA, Vergara JA, et al. (2019) Tuberculosis following PD-1 blockade for cancer immunotherapy. Sci Transl Med 11(475). [cited 2020 Feb 14] Available at: https://www.ncbi.nlm.nih.gov/pubmed/30651320. Accessed $14 \mathrm{Feb} 2020$

16. Lázár-Molnár E, Chen B, Sweeney KA, Wang EJ, Liu W, Lin J, et al (2010) Programmed death-1 (PD-1)-deficient mice are extraordinarily sensitive to tuberculosis. Proc Natl Acad Sci USA 107(30):13402-7 [cited 2020 Feb 15]. Available at: https://www. ncbi.nlm.nih.gov/pubmed/20624978. Accessed 15 Feb 2020

17. Jurado JO, Alvarez IB, Pasquinelli V, Martínez GJ, Quiroga MF, Abbate E, et al. (2008) Programmed death (PD)-1:PD-ligand 1/PD-ligand 2 pathway inhibits $t$ cell effector functions during human tuberculosis. J Immunol 181(1):116-25 [cited 2020 Feb 15]. Available at: https://www.ncbi.nlm.nih.gov/pubmed/18566 376. Accessed 15 Feb 2020

18. Lee JJX, Chan A, Tang T (2016) Tuberculosis reactivation in a patient receiving anti-programmed death-1 (PD-1) inhibitor for relapsed Hodgkin's lymphoma [Internet]. Vol. 55, Acta Oncologica. Taylor and Francis Ltd; 2016 [cited 2020 Feb 14]. p. 519-20. Available at: https://www.ncbi.nlm.nih.gov/pubmed/26754959. Accessed 14 Feb 2020

19. Fujita K, Terashima T, Mio T (2016) Anti-PD1 antibody treatment and the development of acute pulmonary tuberculosis. J Thorac Oncol 11(12):2238-40. [Internet] [cited 2020 Feb 14]. Available at https://www.ncbi.nlm.nih.gov/pubmed/27423391. Accessed 14 Feb 2020

20. Chu YC, Fang KC, Chen HC, Yeh YC, Tseng CE, Chou TY, et al (2017) Pericardial tamponade caused by a hypersensitivity response to tuberculosis reactivation after Anti-PD-1 treatment in a patient with advanced pulmonary adenocarcinoma. J Thor Oncol. 12:e111-4 Elsevier Inc; [cited 2020 Feb 14] Available at https://www.ncbi.nlm.nih.gov/pubmed/28748816. Accessed 14 Feb 2020

21. He W, Zhang X, Li W, Kong C, Wang Y, Zhu L, et al (2018) Activated pulmonary tuberculosis in a patient with melanoma during PD-1 inhibition: A case report. Onco Targets Ther. 11:7423-7427 [cited 2020 Feb 14] Available at: https://www.ncbi.nlm.nih.gov/ pubmed/30425530. Accessed 14 Feb 2020

22. Jensen KH, Persson G, Bondgaard AL, Pøhl M (2018) Development of pulmonary tuberculosis following treatment with antiPD-1 for non-small cell lung cancer. Acta Oncol 57:1127-1128 Taylor and Francis Ltd; [cited 2020 Feb 14]. Available at: https ://www.ncbi.nlm.nih.gov/pubmed/29384034. Accessed 14 Feb 2020

23. Tsai CC, Chen JH, Wang YC, Chang FY (2019) Re-activation of pulmonary tuberculosis during anti-programmed death-1 (PD-1) treatment. QJM 112(1):41-42 [cited 2020 Feb 14] Available at: https://www.ncbi.nlm.nih.gov/pubmed/30351391. Accessed 14 Feb 2020

24. Takata S, Koh G, Han Y, Yoshida H, Shiroyama T, Takada H, et al (2019) Paradoxical response in a patient with non-small cell lung cancer who received nivolumab followed by anti-Mycobacterium tuberculosis agents. J Infect Chemother25(1):54-58 [cited 2020 Feb 14] Available at: https://www.ncbi.nlm.nih.gov/pubme d/30055859. Accessed 14 Feb 2020

25. van Eeden R, Rapoport BL, Smit T, Anderson R (2019) Tuberculosis infection in a patient treated with nivolumab for non-small cell lung cancer: case report and literature review. Front Oncol 9:659 [cited 2020 Feb 14] Available at: https://www.ncbi.nlm. nih.gov/pubmed/31396484. Accessed 14 Feb 2020

26. Anastasopoulou A, Ziogas DC, Samarkos M, Kirkwood JM, Gogas H (2019) Reactivation of tuberculosis in cancer patients following administration of immune checkpoint inhibitors: current evidence and clinical practice recommendations. J Immuno Ther Cancer. BioMed Central Ltd. 7: 239 [cited 2020 Feb 14] Available at: https://jitc.bmj.com/lookup/doi/10.1186/s40425-0190717-7. Accessed 14 Feb 2020

27. Elkington PT, Bateman AC, Thomas GJ, Ottensmeier CH (2018) Implications of tuberculosis reactivation after immune checkpoint inhibition. Am J Respir Criti Care Med Am Thor Soc 198: 14511453 [cited 2020 Jul 27]. Available at: https://pubmed.ncbi.nlm. nih.gov/30141960/. Accessed 27 July 2020

28. Hirashima T, Tamura Y, Han Y, Hashimoto S, Tanaka A, Shiroyama T, et al (2018) Efficacy and safety of concurrent anti-cancer and anti-tuberculosis chemotherapy in cancer patients with active mycobacterium tuberculosis: a retrospective study 11 medical and health sciences 1112 oncology and carcinogenesis. BMC Cancer 18(1):975. [cited 2020 Jul 27]. Available at: https://bmcca ncer.biomedcentral.com/articles/10.1186/s12885-018-4889-1. Accessed 27 July 2020

29. Kim DK, Lee SW, Yoo CG, Kim YW, Han SK, Shim YS, et al. (2005) Clinical characteristics and treatment responses 
of tuberculosis in patients with malignancy receiving anticancer chemotherapy. Chest 128(4):2218-2222 [cited 2020 Jul 27]. Available at https://pubmed.ncbi.nlm.nih.gov/16236877/. Accessed 27 July 2020

30. Dobler CC, Cheung K, Nguyen J, Martin A (2017) Risk of tuberculosis in patients with solid cancers and haematological malignancies: a systematic review and meta-analysis. Eur Respir J. https ://doi.org/10.1183/13993003.00157-2017

31. Kim HR, Hwang SS, Ro YK, Jeon CH, Ha DY, Park SJ, et al. (2008) Solid-organ malignancy as a risk factor for tuberculosis. Respirology 13(3):413-419. [cited 2020 Jul 27] Available at: https://pubmed.ncbi.nlm.nih.gov/18399865/. Accessed 27 July 2020
32. Houben RMGJ, Dodd PJ (2016) The global burden of latent tuberculosis infection: a re-estimation using mathematical modelling. PLOS Med. https://doi.org/10.1371/journal.pmed.1002152

33. AL-Suwaidi Z (2015) Tuberculosis in Qatar. Int J Mycobacteriology 4:124

34. Khattab MA, Khan FY, Al Maslamani M, Al-Khal AL, El Gendy A, Al Soub H et al (2015) pulmonary and extra pulmonary tuberculosis in qatar: a first retrospective population-based study. Adv Infect Dis 05(04):148-153. https://doi.org/10.4236/ aid.2015.54018

Publisher's Note Springer Nature remains neutral with regard to jurisdictional claims in published maps and institutional affiliations. 